\title{
Early Subcutaneous Immunoglobulin for X-Linked Agammaglobulinemia
}

\author{
Alfredo Tagarro* \\ Hospital Universitario Infanta Sofía, San Sebastián de los Reyes Madrid, Spain \\ *Corresponding author: Alfredo Tagarro, Hospital Universitario Infanta Sofía Europa, s/n28702, San Sebastián de \\ los Reyes Madrid, Spain, Tel: +34 606194888, E-mail: alfredo.tagarro@salud.madrid.org
}

\begin{abstract}
Introduction: Subcutaneous immunoglobulin (SCIG) utilization is limited in Spain. Our aim was to describe our experience with SCIG from the diagnosis in a patient with X-linked agammaglobulinemia (XLA).

Case Presentation: A recently diagnosed 6-year-old child with XLA was started on SCIG. A loading dose of $6 \mathrm{~g}$, in three consecutive days ( $2 \mathrm{~g} /$ day) was prescribed. Initially, the aim was trough serum IgG over $500 \mathrm{mg} / \mathrm{dL}$. Nevertheless, 15 months later, IgG levels fell below $500 \mathrm{mg} / \mathrm{dL}$, and some infections occurred. A new aim of $\mathrm{lgG}$ over $700 \mathrm{mg} / \mathrm{dLw}$ was established, after current recommendations. Dose was increased to $3 \mathrm{~g}$ every 7 days. IgG levels rose over 700 $\mathrm{mg} / \mathrm{dL}$, and infections disappeared. Parental evaluation of quality of life is good. No adverse events were reported.
\end{abstract}

Conclusions: SCIG is a valuable choice for treating XLA patients even from the very beginning.

\section{Keywords}

Disease Bruton, X-linked agammaglobulinemia, Immunoglobulins, Immunodeficiency

\section{Introduction}

X-linked agammaglobulinemia (XLA) or Bruton agammaglobulinemia, is an inherited immunodeficiency disease caused by mutations in the gene BTK, that codes for Bruton tyrosine kinase (BTK). In the absence of BTK, B lymphocytes do not differentiate or mature. Without mature B lymphocytes, antibody-producing plasma cells are also absent. Therefore, XLA is characterized by low levels of serum immunoglobulins and almost total or total absence of B lymphocytes and plasma cells.

The current management is the immunoglobulin replacement therapy (IRT). Traditionally, IRT has always been performed with intravenous immunoglobulin (IVIG) every 2-4 weeks. Currently, subcutaneous immunoglobulin (SCIG) is also available. Utilization of SCIG it is still limited in Spain. Physicians are often unfamiliar with its use, and availability is limited at many hospitals. Generally, the use of SCIG is sequential, after a loading dose IVIG.

In this case report, we review the case of a school-age boy with XLA, who was successfully treated with SCIG from diagnosis.

\section{Case Report}

A 6-years old male was attended in May 2012 at the Pediatric Infectious Diseases clinics for recurrent infections (diarrhea and chronic suppurative otitis media). He was the first kid of 2 siblings. Her sister was a 4-year-old healthy girl. There was no antecedents of suspected or confirmed immunodeficiency in any part of the family tree. There were no deaths at an early age in grandparents, uncles, aunts or cousins.

Upon suspicion of primary immunodeficiency with concurrent infections, immune study was requested. The study of immunoglobulins by turbidimetry showed the following results: IgG $458 \mathrm{mg} / \mathrm{dL}$, IgA $<33$ $\mathrm{mg} / \mathrm{dL}$ (verified by nephelometry: high sensitivity $\operatorname{IgA}<6 \mathrm{mg} / \mathrm{dL}$ ) and IgM $<21 \mathrm{mg} / \mathrm{dL}$. A mutation was found in the BTK gene (located in Xq22.1). Laboratory tests confirmed a profoundly diminished (15\%) expression. B cell levels were $0.34 \% \mathrm{CD} 19+$. After deliberation with the parents, we decided to start on SCIG 20\% (Hizentra ${ }^{\circ}, 200 \mathrm{mg} / \mathrm{mL}$, CLS Behring, Marburg, Germany), by infusion pump. The initial goal was to keep IgG over $500 \mathrm{mg} / \mathrm{dL}$, following recommendations [1]. An initial loading dose of $6 \mathrm{~g}(322 \mathrm{mg} / \mathrm{kg})$ was administered over 3 consecutive days, at 2 grams daily $(107 \mathrm{mg} / \mathrm{kg} /$ day $)$. The first three doses were administered in the hospital daycare facility, without premedication. During these three days, the parents were trained in infusion technique. There were no complications. The following doses were administered at home, at a rate of $2 \mathrm{~g}$ every 7 days $(107 \mathrm{mg} / \mathrm{kg} /$ week, $428 \mathrm{mg} / \mathrm{month})$ (Figure 1). An analysis on day +10 showed that levels of IgG were 869 $\mathrm{mg} / \mathrm{dL}$. Infusion was changed to $2 \mathrm{~g}$ every 10 days ( $321 \mathrm{mg} / \mathrm{month})$. The following +10 levels were $465 \mathrm{mg} / \mathrm{dL}$, so we returned to $2 \mathrm{~g}$ every 7 days (428 gr/month).

In March 2014, persistent infections (1 perianal streptococcal infection, 2 giardiasis, 1 herpes zoster, 1 otitis) were recorded. Other, more recent publications were consulted suggesting that higher levels are more effective at preventing infections [2]. The dose was increased to $3 \mathrm{~g}$ ( $140 \mathrm{mg} / \mathrm{kg} / 10$ days, $420 \mathrm{mg} / \mathrm{kg} / \mathrm{month})$ every 10 days. In May 2014 , the dose was increased to $3 \mathrm{~g}$ every 7 days $(139 \mathrm{mg} / \mathrm{kg} /$ week, 558 $\mathrm{mg} / \mathrm{kg} / \mathrm{month}$ ).

To date, the patient has had no further infections or cough. No systemic adverse effects were reported. The only adverse event was a transient local induration after infusions. The perceived quality of the parents and the patient's attitude is good. 


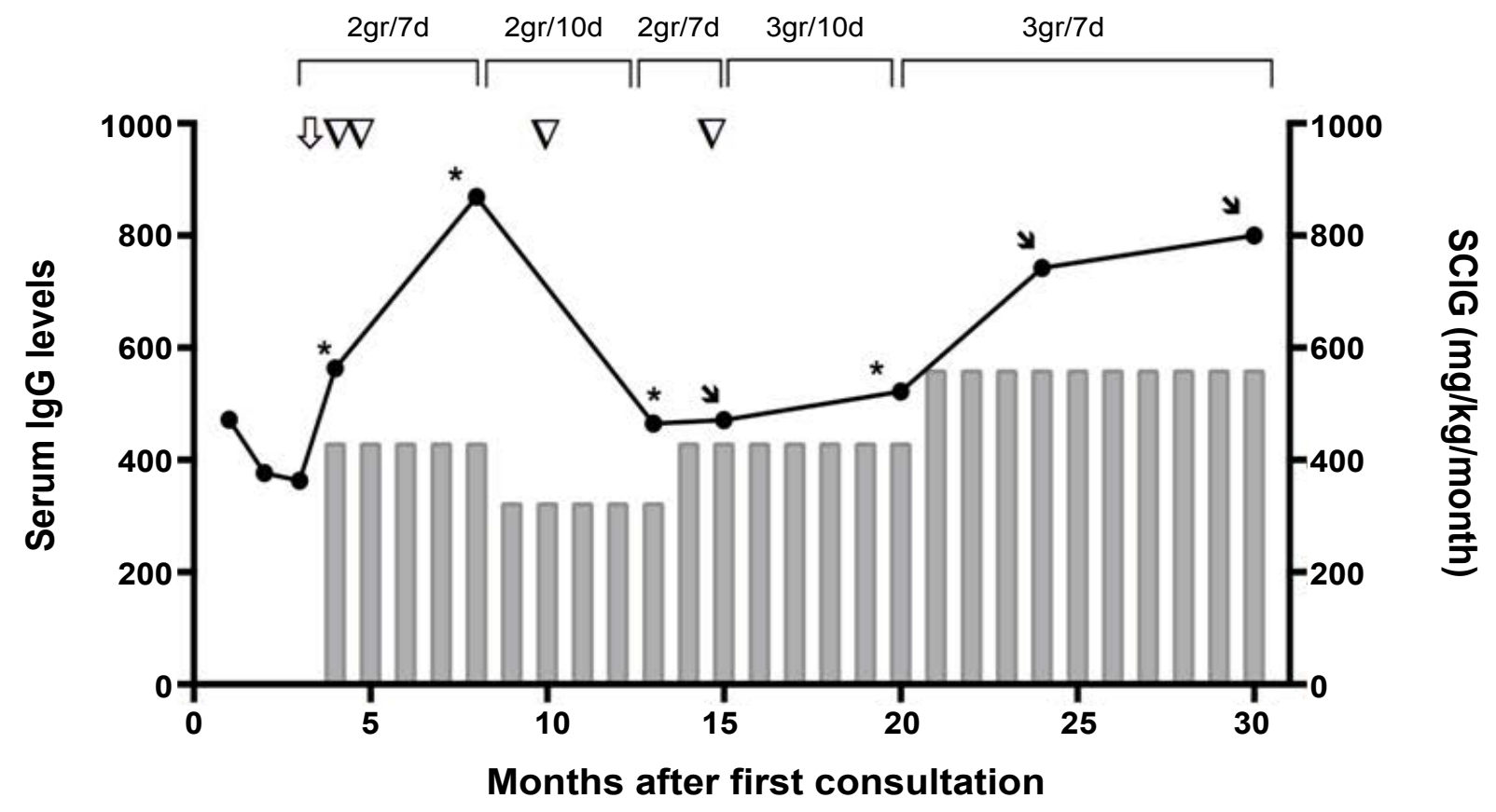

\section{Serum lgG 』SCIG dose ( $\mathrm{mg} / \mathrm{kg} / \mathrm{month})$}

Figure 1: Evolution of IgG levels and subcutaneous immunoglobulin (SCIG) along time.

$\sqrt{\Omega}$ : Starting of SCIG treatment

$\nabla:$ Infection episode

*: Day +10 through

y: Day +7 through

\section{Discussion}

The interest of the case lies in the beginning of the replacement therapy directly with SCIG, without intravenous loading dose. Also, the clinical outcome was better with higher levels of IgG. The tolerance to the treatment was good during the first 3 years of therapy.

Until recently, the only IRT for ALX in Spain was IVIG. In 2012, one paper described a series of 4 patients that were started on $16 \%$ SCIG, but all patients received a loading dose of IGIV (400 and $600 \mathrm{mg} / \mathrm{kg}$ ) before SCIG [3]. The practice of giving an intravenous infusion of IVIG for reaching higher levels more quickly is usual, but may not be necessary. IVIG has systemic side effects in $<6 \%$ of patients (versus $<3 \%$ with SCIG) and requires premedication in a significant proportion of patients. SCIG allows for more stable and physiological levels. The number of infections is inversely proportional to IgG levels [4]. From 2014, this patient was labeled with a new target levels over $700 \mathrm{mg} / \mathrm{dL}$. Patient infections decreased in number and severity. A number of papers suggest that through levels are not necessary for the follow-up of patients on SCIG [4]. According these authors, the clinicians should have the absence of serious infections as a goal, rather than a serum IgG level threshold. The biological level might be different for each patient [5-8].

Relating costs, the cost of SCIG can be up to $25 \%$ less than the cost of IRT with IGIV [6].

In conclusion, IRT with SCIG since the very beginning of the treatment of XLA is safe. SCIG is an attractive option for managing patients requiring IRT.

\section{References}

1. Maarschalk-Ellerbroek LJ, Hoepelman IM, Ellerbroek PM (2011) Immunoglobulin treatment in primary antibody deficiency. Int $\mathrm{J}$ Antimicrob Agents 37: 396-404.

2. Berger M (2011) Incidence of infection is inversely related to steady-state (trough) serum IgG level in studies of subcutaneous IgG in PIDD. J Clin Immunol 31: 924-926.

3. GarcíaCasas P, González-Granado LI (2012) Experiencia con inmunoglobulinasubcutánea en inmunodeficiencias humorales. Acta Pediatr Esp 70: 385-391.

4. Berger M Subcutaneous and intramuscular immune globulin therapy.

5. Ballow M (2013) Optimizing immunoglobulin treatment for patients with primary immunodeficiency disease to prevent pneumonia and infection incidence: review of the current data. Ann Allergy Asthma Immunol 111: S2S5.

6. Orange JS, Grossman WJ, Navickis RJ, Wilkes MM (2010) Impact of trough IgG on pneumonia incidence in primary immunodeficiency: A meta-analysis of clinical studies. Clin Immunol 137: 21-30.

7. Bonagura VR, Marchlewski R, Cox A, Rosenthal DW (2008) Biologic IgG level in primary immunodeficiency disease: the lgG level that protects against recurrent infection. J Allergy Clin Immunol 122: 210-212.

8. Beauté J, Levy P, Millet V, Debré M, Dudoit Y, et al. (2010) Economic evaluation of immunoglobulin replacement in patients with primary antibody deficiencies. Clin Exp Immunol 160: 240-245. 